\title{
Factors associated with vitamin $D$ status of low- income, hospitalized psychiatric patients: results of a retrospective study
}

This article was published in the following Dove Press journal:

Neuropsychiatric Disease and Treatment

15 November 2016

Number of times this article has been viewed

\author{
Alessandra N Bazzano' \\ Lisa Littrell' \\ Stephen Lambert ${ }^{2}$ \\ Cody Roi $^{2}$ \\ 'Department of Global Community \\ Health and Behavioral Sciences, \\ Tulane University School of Public \\ Health and Tropical Medicine, Tulane \\ University, ${ }^{2}$ Department of Psychiatry, \\ Louisiana State University Health \\ Sciences Center, Louisiana State \\ University, New Orleans, LA, USA
}

Background: Recent evidence has indicated a potential role of vitamin D3 in a range of neuropsychiatric outcomes, as well as on cognitive function, but conflicting data have left that role uncertain. Understanding potential associations of vitamin D status with psychiatric illness will allow clinicians to better assess therapeutic options. Few studies have examined vitamin D status among a racially diverse group of psychiatric patients who have been hospitalized, and none has done so in the southern US where socioeconomic inequality is high.

Methods: In this retrospective study, medical records from 113 patients hospitalized for psychiatric illness were retrieved and analyzed. Vitamin D status in this population was estimated, along with any patterns of association between deficiency and risk factors.

Results: The vast majority of patients hospitalized for psychiatric illness in this biracial, lowincome sample had either insufficient or deficient vitamin D levels. African-American patients had lower levels of vitamin D than Caucasian patients.

Discussion: Our findings demonstrate that hospitalized psychiatric patients are at increased risk for vitamin D deficiency and in particular low-income, African-American populations. These results suggest that vitamin D should be assessed and therapy considered at the initiation of psychiatric hospitalizations.

Keywords: vitamin D, psychiatric diagnosis, cognitive function, neuropsychological function

\section{Introduction}

The association between low vitamin D3 serum levels and neuropsychiatric conditions has been the subject of a number of recent research studies. Technically a steroid hormone, vitamin D3 and its receptor VDR (vitamin D receptor) have become more widely implicated in various health and disease states beyond osteomalacia, or rickets, as information on their function in the body has emerged over the past three decades. ${ }^{1}$ Deficiency of vitamin D3 (also known as cholecalciferol) has arisen as a possible risk factor for a range of mental health conditions. ${ }^{2,3}$ Preclinical studies and epidemiological research support the contention that prenatal deficiency of vitamin D impairs fetal neurodevelopment potentially contributing to developmental disability in childhood or psychiatric conditions such as schizophrenia in adulthood. ${ }^{4,5}$ Similar findings have been identified in animal models. ${ }^{6,7}$ Numerous clinical studies have also shown that low levels of vitamin D are directly or indirectly linked to adult psychiatric conditions including depression and cognitive impairment. ${ }^{8-10}$ Clinical studies ${ }^{11,12}$ have implied a relationship between low vitamin D levels and conditions such as depression, ${ }^{13,14}$ substance abuse, ${ }^{15}$ schizophrenia, ${ }^{16,17}$ delirium, ${ }^{18}$ and suicidal ideation. ${ }^{19}$
Correspondence: Alessandra N Bazzano Department of Global Community Health and Behavioral Sciences, Tulane University School of Public Health and Tropical Medicine, Tulane University, I440 Canal St, New Orleans,

LA 70I I2, USA

Email abazzano@tulane.edu 
Deficiency of vitamin D is common in North America and in the past decade has been described as a major public health problem. ${ }^{2}$ Data from the National Health and Nutrition examination surveys demonstrate that about one-quarter of the US population could be categorized as having insufficient vitamin D levels, and about 7\%, frank deficiency. ${ }^{20} \mathrm{~A}$ study of healthy preschool-aged African-American children from low-income families in Atlanta, Georgia, reported 26\% had low vitamin D levels. ${ }^{21}$ Some risk factors associated with vitamin D deficiency include insufficient sunlight, dark skin, old age, obesity, diabetes, and medications that alter vitamin D absorption, in particular medications such as anticonvulsants, steroids, or antiretrovirals. ${ }^{18,22-25}$ Residing at higher latitude also represents a risk factor for insufficient vitamin $\mathrm{D}$, particularly latitudes more northerly than $35^{\circ} \mathrm{N} .{ }^{26}$

Prior descriptive studies have provided evidence that vitamin D deficiency is especially prevalent in the psychiatric inpatient setting, but the literature is inconsistent. In a psychiatric hospital in the UK, researchers found that $83 \%$ of patients had vitamin D deficiency and $92 \%$ had below optimal levels of vitamin D. ${ }^{27}$ Menkes et $\mathrm{al}^{28}$ identified a link between decreased level of vitamin $\mathrm{D}$ in psychiatric patients and poor physical health outcomes. Psychiatric patients may be exposed to additional physical risk factors associated with low vitamin D states such as cardiovascular disease. ${ }^{29-31}$ Psychiatric patients may also be at risk for vitamin D deficiency due to their age, less exposure to sunlight, and dietary factors. ${ }^{28}$ Sufficient levels of vitamin $D$ are protective against infectious diseases, autoimmune disorders, type 1 and type 2 diabetes, musculoskeletal disorders, infertility, and adverse pregnancy and birth outcomes. ${ }^{32}$

Among psychiatric illnesses, vitamin D supplementation has been extensively studied in depression, as a potential factor in improvement of mood. ${ }^{33,34}$ Vitamin D supplementation is likely to be only one part of treatment, as depression has myriad causes, yet its use could be important as research has indicated that vitamin D deficiency impairs and extends recovery from depression. ${ }^{33}$ Gezen-Ak et al ${ }^{35}$ reported that vitamin $\mathrm{D}$ treatment increased the production of glia-derived neurotrophic factor (GDNF). Neurotrophins like GDNF enhance the survival and growth of neurons. Since other neurotrophins (eg, brain-derived neurotrophic factor) and vascular endothelial growth factor are low in depression, the effects of vitamin D on GDNF could be important to its antidepressant effects.

Many of the characteristics linked with insufficient vitamin D levels are present in the psychiatric patient population in New Orleans, Louisiana $\left(29.95^{\circ} \mathrm{N}\right)$, a southern US city that has undergone two recent, major natural disasters that have exacerbated mental health issues. ${ }^{36,37}$ The state is currently underresourced with regard to health facilities and providers dedicated to mental health; the National Association of State Mental Health Program Directors Research Institute reported in 2009 that Louisiana spent $\$ 60.89$ per resident for psychiatric institutes and administrative costs in state mental health spending, representing $60 \%$ less than the national average of $\$ 104.10 .^{38}$ Statewide budget cuts over the past several years, and reduced spending on mental health services have resulted in a fragmented behavioral health system. ${ }^{39}$

However, there is little knowledge regarding the actual vitamin D status of psychiatric inpatients in Louisiana and no studies to date on this population. This study aimed to determine the point prevalence of hypovitaminosis D in a local inpatient psychiatric population and to assess any potential relationships between vitamin D levels and risk factors for vitamin D deficiency such as age, gender, race/ethnicity, psychiatric diagnosis, medical diagnosis, length of stay, severity of illness (measured by number of psychiatric hospitalizations), and routine lab measurements obtained during psychiatric hospitalization. This study presents the results of a retrospective chart review with implications for clinical practice.

\section{Methods}

We undertook a retrospective chart review utilizing the medical records of the Louisiana State University Health Sciences Center (LSU-HSC), a hospital with a majority of low-income patients who are either uninsured or underinsured. A list of medical records of adult patients aged 18-65 years, admitted to the LSUHSC inpatient psychiatric unit, were obtained and reviewed. Eligibility criteria included patients with at least one psychiatric diagnosis, one or more inpatient psychiatric hospitalizations since May 1, 2012, and with at least one of those hospitalizations being at the LSU-HSC inpatient unit. Eligible patient records must have also included a vitamin D hydroxy test taken on admission and dated between May 1, 2012, and November 1,2014 . This test is commonly utilized for diagnostic purposes, as it is thought to be a good indicator of exogenous sources of vitamin $\mathrm{D}$ such as diet, sunlight exposure, or supplementation. Measurements are based on total 25(OH)D, with levels $<20.0$ $\mathrm{ng} / \mathrm{mL}$ indicative of vitamin D deficiency. Insufficient $25(\mathrm{OH})$ $\mathrm{D}$ is defined by levels between 20.0 and $31.9 \mathrm{ng} / \mathrm{mL}$ and normal $25(\mathrm{OH}) \mathrm{D}$ by levels $>31.9 \mathrm{ng} / \mathrm{mL}$. Exclusion criteria included the following: 1) patients for whom the primary diagnosis was 
a medical condition at the time of discharge, 2) patients for whom no psychiatric diagnosis could be established or was reported at the time of discharge, 3) patients taking vitamin D supplements at the time of admission, or patients who had taken vitamin D supplements regularly in the 3 months leading up to admission.

The data collected from the 113 patient records included in this study were anonymized at the time of export from electronic medical records, initially assessed in Microsoft Excel (2013), and then subsequently imported for further analysis into SPSS Statistical Package for Windows (Version 23; IBM Corporation, Armonk, NY, USA). The data set was cleaned by an experienced data analyst. The sample utilized for analysis represented the maximum number of electronic medical records available for the researchers to review according to institutional and logistical constraints.

Variables with missing information were coded as " 998 " and were accounted for in the results and analysis. Previous literature $\mathrm{e}^{23,40}$ has described older age and dark skin as potential risk factors associated with vitamin D deficiency and, therefore, "age" was recoded from a continuous to a dichotomous variable with a cutoff value of 50 years and "race/ethnicity" was recoded from a categorical to a dichotomous variable of Caucasian and non-Caucasian. The continuous variable of "vitamin D" was maintained in its original form as well as recorded into a categorical variable in which values $<20 \mathrm{ng} /$ $\mathrm{mL}$ were categorized as vitamin $\mathrm{D}$ deficient, values of 20-31.9 $\mathrm{ng} / \mathrm{mL}$ as vitamin D insufficient, and values $>31.9 \mathrm{ng} / \mathrm{mL}$ as normal vitamin D status in accordance with the LSU-HSC standard values. Descriptive statistics, or univariate analysis, was run on the sample to obtain frequencies, point prevalence, means, standard deviations, and interquartile ranges.

The Institutional Review Boards of LSU-HSC and Tulane University both reviewed the study and deemed it exempt from ethical approval. Due its to retrospective nature and use of only de-identified data, patient consent was not required for this study.

\section{Results}

\section{Sample characteristics}

As illustrated in Table 1, the total sample size was 113. The average age of psychiatric inpatients included in the sample was 44 years, where $56.6 \%$ were male and $43.4 \%$ were female, and $59.3 \%$ were African American. A majority of the sample population $(65.5 \%)$ were unemployed at the time of admission, and for $92.9 \%$ of the sample, this was not the first admission into a psychiatric inpatient care facility. The average length of stay at LSU-HSC was about 2 weeks (13.4 days).
Table I Sample characteristics (N=||3)

\begin{tabular}{|c|c|c|c|}
\hline Characteristics & Percent (\%) & Mean of sample & (n) \\
\hline \multicolumn{4}{|l|}{ Age } \\
\hline Average age & & 44 years & \\
\hline$>50$ years & 42.5 & & 48 \\
\hline$<50$ years & 57.5 & & 65 \\
\hline \multicolumn{4}{|l|}{ Gender } \\
\hline Female & 43.4 & & 49 \\
\hline Male & 56.6 & & 64 \\
\hline \multicolumn{4}{|l|}{ Race/ethnicity } \\
\hline African American & 59.3 & & 67 \\
\hline Caucasian & 33.6 & & 38 \\
\hline Hispanic & 3.5 & & 4 \\
\hline Other & 2.7 & & 3 \\
\hline Did not specify & 0.9 & & 1 \\
\hline \multicolumn{4}{|l|}{ Employment status } \\
\hline Employed & 8 & & 9 \\
\hline Unemployed & 65.5 & & 74 \\
\hline Did not specify & 26.5 & & 30 \\
\hline \multicolumn{4}{|l|}{ Admission history } \\
\hline Length of stay & & I3.4 days & \\
\hline >I Admission & 92.9 & & 105 \\
\hline \multicolumn{4}{|c|}{ Vitamin D status on admission } \\
\hline Average level (ng/dL) & & 22.5 & \\
\hline Normal (30-100 ng/dL) & 15.0 & & 16 \\
\hline Insufficient (20-30 ng/dL) & 36.3 & & 41 \\
\hline Deficient $(<20 \mathrm{ng} / \mathrm{dL})$ & 48.7 & & 55 \\
\hline \multicolumn{4}{|l|}{ Psychiatric diagnosis } \\
\hline Schizophrenia & 32.7 & & 37 \\
\hline Bipolar I disorder & 34.5 & & 39 \\
\hline Major depressive disorder & 29.2 & & 33 \\
\hline Depression NOS & 30.1 & & 34 \\
\hline Schizoaffective disorder & 21.1 & & 24 \\
\hline Psychosis unspecified & 18.6 & & 21 \\
\hline Anxiety disorder & 13.3 & & 15 \\
\hline \multicolumn{4}{|l|}{ Drug abuse disorder } \\
\hline Alcohol use & 60.2 & & 68 \\
\hline Cannabis use & 52.5 & & 59 \\
\hline Opiate use & 28.2 & & 32 \\
\hline Cocaine use & 41.6 & & 47 \\
\hline \multicolumn{4}{|l|}{ Medical diagnosis } \\
\hline Hypertension & 38.9 & & 44 \\
\hline Hyperlipidemia & 10.6 & & 12 \\
\hline Diabetes & 14.2 & & 16 \\
\hline
\end{tabular}

Abbreviation: NOS, not otherwise specified.

\section{Vitamin D levels}

Table 2 presents the results for vitamin D status among the sample. Only $15 \%$ of patients in the sample had a normal vitamin D level. Mean vitamin D status on admission was insufficient $(22.5 \mathrm{ng} / \mathrm{mL})$ and at the lower end of the vitamin D insufficiency range (20-31.9 $\mathrm{ng} / \mathrm{mL})$ verging on deficient. Although the mean level of vitamin D on admission was in the insufficiency range, nearly one-half (48.7\%) of the sample population was admitted with deficient levels of vitamin D $(<20 \mathrm{ng} / \mathrm{mL})$. Vitamin D levels were also 
Table 2 Vitamin D status by selected sample characteristics $(\mathrm{N}=1$ I3)

\begin{tabular}{|c|c|c|c|c|c|}
\hline & $\begin{array}{l}\text { Deficient } \\
\%(n)\end{array}$ & $\begin{array}{l}\text { Insufficient } \\
\%(n)\end{array}$ & $\begin{array}{l}\text { Normal } \\
\%(n)\end{array}$ & $\begin{array}{l}\text { Number in } \\
\text { category }(n)\end{array}$ & $\begin{array}{l}\text { Mean vitamin D levels } \\
\mathrm{ng} / \mathrm{mL} \text { (SD) }\end{array}$ \\
\hline Sample & $48.7(55)$ & $36.3(4 I)$ & $15.0(17)$ & 113 & 22.57 ( 11.09$)$ \\
\hline \multicolumn{6}{|l|}{ Age } \\
\hline$>50$ years & $50.0(24)$ & $31.1(15)$ & $18.8(9)$ & 48 & 23.49 (I3.47), $P=0.586$ \\
\hline$<50$ years & $47.7(31)$ & $40.0(26)$ & $12.3(8)$ & 65 & $21.87(8.98)$ \\
\hline \multicolumn{6}{|l|}{ Gender } \\
\hline Male & $37.5(24)$ & $37.5(24)$ & $25.0(16)$ & 64 & 24.28 (II.34), $P=0.058$ \\
\hline Female & $63.3(31)$ & $26.5(13)$ & $10.2(5)$ & 49 & $20.30(10.43)$ \\
\hline \multicolumn{6}{|l|}{ Race/ethnicity } \\
\hline Non-Caucasian* & $60.6(43)$ & $29.6(21)$ & $9.9(7)$ & 71 & 20.94 (II.75), $P=0.035$ \\
\hline Caucasian & $29.3(12)$ & $46.3(19)$ & $24.4(10)$ & 41 & $25.61(9.19)$ \\
\hline \multicolumn{6}{|l|}{ Psychiatric disorder } \\
\hline Schizophrenia & $51.4(19)$ & $35.1(13)$ & I $3.5(5)$ & 37 & $21.8 \mathrm{I}(\mathrm{I} \mid .94), P=0.623$ \\
\hline Bipolar I & $46.2(18)$ & $33.3(13)$ & $20.5(8)$ & 39 & 24.62 (13.53), $P=0.152$ \\
\hline Major depressive disorder & $42.4(14)$ & $42.4(14)$ & I5.2(5) & 33 & 21.95 (9.37), $P=0.7 \mid 3$ \\
\hline Depression NOS & $44.1(15)$ & $32.4(1 \mathrm{I})$ & $23.5(8)$ & 34 & $24.01(10.14), P=0.361$ \\
\hline Schizoaffective disorder & $58.3(14)$ & $37.5(9)$ & $4.2(1)$ & 24 & $19.98(8.3 \mathrm{I}), P=0.20 \mathrm{I}$ \\
\hline Psychosis unspecified & $71.4(15)$ & $14.3(5)$ & $14.3(3)$ & 21 & 19.25 ( 11.49$), P=0.131$ \\
\hline Anxiety disorder & $33.3(5)$ & $53.3(8)$ & I3.3 (2) & 15 & 23.7I (I I.22), $P=0.668$ \\
\hline \multicolumn{6}{|l|}{ Substance abuse disorder } \\
\hline Alcohol & $50.0(34)$ & $29.4(20)$ & $20.6(14)$ & 68 & 23.45 ( $(2.58), P=0.298$ \\
\hline Cannabis & $49.2(29)$ & $37.3(22)$ & $13.6(8)$ & 59 & 22.32 (II.I5), $P=0.754$ \\
\hline Opiates & $43.8(14)$ & $34.4(11)$ & $21.9(7)$ & 32 & 23.58 (II.52), $P=0.978$ \\
\hline Cocaine & $42.6(20)$ & $44.7(21)$ & $12.8(6)$ & 47 & 23.47 (II.85), $P=0.639$ \\
\hline
\end{tabular}

Notes: *Non-Caucasian includes African American and Hispanic. Medical records indicating race/ethnicity as "Other", or where none was specified were treated as missing values $(n=4)$.

Abbreviation: NOS, not otherwise specified.

analyzed categorically; $36.3 \%$ had insufficient vitamin D levels (20-31.9 ng/mL) and 48.7\% deficient vitamin D levels $(<20 \mathrm{ng} / \mathrm{mL})$.

The lowest mean levels of vitamin D were found among patients diagnosed with schizoaffective disorder (19.98 ng/mL) and unspecified psychosis (19.25 ng/mL); however, the results were not statistically significant ( $P=0.201$ and 0.131 , respectively). The most common psychiatric diagnoses were bipolar 1 disorder $(34.5 \%)$, schizophrenia (32.7\%), and depression not otherwise specified (30.1\%). Other diagnoses included major depressive disorder, schizoaffective disorder, unspecified psychosis, and anxiety disorder. Alcohol use (60.2\%) and cannabis use (52.5\%) were the most common substance abuse disorders, followed closely by cocaine use (41.6\%). A little over a quarter of the sample $(28.2 \%)$ had a diagnosis of opiate abuse disorder. Less than half of the sample population had any compounding medical diagnosis. These included cardiovascular diseases such as hypertension (38.9\%) and hyperlipidemia (10.6\%), and either type 1 or type 2 diabetes (14.2\%), where no significant differences were found with regard to vitamin $\mathrm{D}$ status.

Age also did not result in any significant differences in this sample. For those over the age of 50 years, half (50\%) were deficient in vitamin $\mathrm{D}$, and for those under the age of 50 years, $47.7 \%$ were deficient. The mean vitamin D levels for gender were significantly different $(P=0.058)$, where females were found to have a mean vitamin $D$ level of $20.30 \mathrm{ng} / \mathrm{mL}$ and males a mean value of $24.28 \mathrm{ng} / \mathrm{mL}$. Race/ ethnicity was also found to have significantly different mean values of vitamin $\mathrm{D}(P=0.035)$. Caucasian patients had a mean vitamin D level of $25.61 \mathrm{ng} / \mathrm{mL}$, while non-Caucasians had a mean value of $20.94 \mathrm{ng} / \mathrm{mL}$. This translates into $60.6 \%$ of non-Caucasians being vitamin D deficient compared to Caucasians, among whom $29.3 \%$ were deficient.

All patients in this sample had at least one psychiatric diagnosis but may have had more than one. Therefore, it was impossible to compare deficiency within the category of psychiatric diagnosis. Looking at univariate analysis, however, it is evident that $51.4 \%$ of schizophrenics were vitamin D deficient and $35.1 \%$ were insufficient. Of those with bipolar 1 disorder, $46.2 \%$ had deficient vitamin D levels and 33.3\% had insufficient levels. It is interesting to note that the prevalence of non-normal vitamin D levels in those with bipolar 1 disorder was not greatly different from those without bipolar 1 disorder, who had values of $50 \%$ and $37.8 \%$ for deficiency and insufficiency, respectively. Similar results were found in those with depression and schizoaffective disorder, in that 
there is almost no difference between deficiency levels of vitamin D in those with the disorder compared to those without the disorder $(22.85$ and $22.27 \mathrm{ng} / \mathrm{mL}$, respectively, for any depression diagnosis; 19.98 and $28.25 \mathrm{ng} / \mathrm{mL}$, respectively, for schizoaffective disorder).

Unspecified psychosis and anxiety disorder showed a larger difference in deficient levels of vitamin $\mathrm{D}$ in those with the disorder compared to those without the disorder $(71.4 \%$ and $43.5 \%$, respectively, for unspecified psychosis and $33.3 \%$ and $51 \%$, respectively, for anxiety disorders). However, their mean vitamin D levels remained insignificant $(P=0.131$ for unspecified psychosis and $P=0.668$ for anxiety disorders). As stated, all study subjects had at least one psychiatric diagnosis but many had more than one from a previous hospitalization in a different facility or following evaluation by a non-LSUHSC health provider. For this reason, we could not ascertain with certainty why depression and schizoaffective disorder exhibited almost no difference in vitamin D deficiency or why bipolar 1 disorder resulted in the reported values. Future investigations, such as a case-control or a chart review, that include patients with non-psychiatric diagnoses may offer better solutions in explaining these possible differences.

Substance abuse did not result in significantly different mean deficiency levels between those with a substance abuse disorder and those without the disorder. Fifty percent of those with an alcohol use disorder were vitamin D deficient but $46.7 \%$ of those without an alcohol disorder were also vitamin D deficient. There was almost no difference in cannabis users, with $49.2 \%$ of users being deficient in vitamin $\mathrm{D}$ and $49.1 \%$ of nonusers also being deficient. A total of $43.8 \%$ of opiate users and $50.6 \%$ of non-users were vitamin D deficient. Similarly, $42.6 \%$ of cocaine users and $55 \%$ of non-users were vitamin D deficient. As with psychiatric diagnosis, and due to the nature of this study, it was not possible to explore these results beyond univariate analysis.

\section{Discussion}

To date, this is the first study to determine the point prevalence of vitamin D deficiency in a psychiatric hospital patient population in Louisiana. Serum 25(OH)D levels in our sample indicate a high prevalence of vitamin D deficiency and insufficiency among hospitalized psychiatric patients. These results are consistent with similar studies conducted by Zeng et al in the US Midwest, ${ }^{41}$ McCue et al in New York, ${ }^{22}$ Berk et al in Australia, ${ }^{11}$ and Humble et al in northern Europe ${ }^{42}$ However, in our study, $85 \%$ of the sampled patients had lower than normal vitamin $\mathrm{D}$, a much higher level than that identified in similar studies. A 2016 cross-sectional study in the US determined the prevalence of vitamin D deficiency among psychiatric inpatients and found that $30 \%$ of patients had sufficient levels, ${ }^{41}$ double that of the present study. Per Centers for Disease Control data, 20\%-25\% of North American people are considered to be vitamin D insufficient and 7\% had hypovitaminosis D. ${ }^{43}$

Our mean 25(OH)D value was also lower than the levels found generally in the US population, as illustrated by the 2009-2010 NHANES sample, where the mean was $25.67 \mathrm{ng} / \mathrm{mL} .{ }^{43}$ The mean vitamin D level for this sample was $22.56 \mathrm{ng} / \mathrm{mL}$. The standard deviation at the first stage of analysis was 11.086, which indicates a wide range of variation around the mean. Upon closer inspection it was found that the study sample contained 3 outlying values, and when those values were set to missing and the analysis rerun, the mean vitamin D level decreased slightly to $21.49 \mathrm{ng} / \mathrm{mL}$ and the standard deviation decreased to 9.016. Because most nutrients are positively skewed, the skewed nature of this sample is to be expected and, therefore, the outlying values were maintained in the study sample.

Despite being lower than in the general population, the mean serum 25(OH)D level in our study was slightly higher than the levels observed in other similar studies conducted in psychiatric hospital settings: $20.9 \mathrm{ng} / \mathrm{mL}$ in long-term psychiatric inpatients in Virginia, ${ }^{44} 17.2 \mathrm{ng} / \mathrm{mL}$ in psychiatric inpatients and outpatients in Norway, ${ }^{20}$ and $<20 \mathrm{ng} / \mathrm{mL}$ among the psychiatric patients in a London hospital. ${ }^{27}$ The differences are likely due to the latitude of New Orleans being lower than that found in other studies, though they could also represent increased risk factors for vitamin D deficiency among a lower socioeconomic status population. For example, our study indicated lower levels than those found in psychiatric patients in the US Midwest $(26.7 \mathrm{ng} / \mathrm{mL})$ where socioeconomic status is higher though latitude is more northerly. ${ }^{45}$

The intensity of ultraviolet (UV) light in the critical 290-315 nm waveband reaching the earth's surface is determined by the zenith angle of the sun, which varies considerably with the month of the year and with latitude ${ }^{46}$ affecting the amount of $25(\mathrm{OH}) \mathrm{D}$ level related to sun exposure. ${ }^{2}$ Kimlin et $\mathrm{al}^{47}$ reported that increase in latitude dramatically decreases the amount of vitamin D UV, which may inhibit vitamin D synthesis in humans. New Orleans is situated at latitude $29.9^{\circ} \mathrm{N}$, so vitamin D synthesis should be higher as compared to other locations mentioned earlier. Generally, people who live at higher than $35^{\circ} \mathrm{N}$ latitudes are at increased probability of having vitamin D insufficiency, which also explains the differences in serum $25(\mathrm{OH}) \mathrm{D}$ levels from our 
study and other studies conducted in different people living in different latitudes. ${ }^{42,47}$ The highest level is mostly observed 2 months after the summer in the northern hemisphere. ${ }^{42}$ Lucas et $\mathrm{al}^{48}$ showed this seasonal variation with a lag of 8 weeks between the maximum monthly UV dose and the peak $25(\mathrm{OH}) \mathrm{D}$ level. The time taken to establish the steady state of a compound is $\sim 3-4$ times its half-life, which for $25(\mathrm{OH}) \mathrm{D}$ is about 22 days. Thus, this lag period may represent the time taken to establish a new steady state. ${ }^{48,49}$ The $25(\mathrm{OH}) \mathrm{D}$ level variation in our study may be related to sample collection during this period. It is also possible that some of these differences can be due to the different $25(\mathrm{OH}) \mathrm{D}$ assay methods applied by different laboratories. ${ }^{50}$

African American patients had significantly lower vitamin D levels compared to Caucasian patients in our study. According to the April 2010 US census, the racial composition of New Orleans that consisted of $60.2 \%$ African American and 33\% Caucasian population, respectively, ${ }^{51}$ was similar to the racial composition of our study, indicating that race or ethnicity may play an important part when determining confounding factors for vitamin D status in psychiatric patients. The sample for this study is representative of the two major racial groups in the New Orleans population, and this largely excludes the possibility that the difference was associated with sample collection but could be due to differences in skin pigmentation. ${ }^{52}$ Anything that can cause interference with the penetration of sunlight into the skin will affect the synthesis of vitamin D3, and melanin is extremely efficient in absorbing sunlight, leading to reduction in vitamin D3 synthesis. ${ }^{53}$ Some studies have hypothesized that vitamin D insufficiency could account for the increased risk of schizophrenia observed among dark-skinned immigrant people. ${ }^{54,55}$ Based on our data, no sufficient evidence is available to support or refute this hypothesis.

Cardinal and Gregory ${ }^{27}$ and Humble ${ }^{26}$ indicated that vitamin $\mathrm{D}$ deficiency is related to increased age. ${ }^{26,27}$ In this study, however, $31.1 \%$ patients were $>50$ years of age and $40 \%$ were $<50$ years of age and we did not observe any significant difference in vitamin $\mathrm{D}$ levels between those two groups, though gender was borderline significant. Several investigators have shown that low vitamin D levels are significantly associated with cardiovascular risk factors, obesity, ${ }^{24}$ and diabetes. ${ }^{25}$ Though it is common to find these medical illnesses coexisting with lower vitamin D levels, this study identified no significant correlation between them. Based on the risk of metabolic syndrome being related to antipsychotic medications use, which might be related to vitamin D deficiency, the effect of antipsychotic medications on vitamin $\mathrm{D}$ levels remains elusive. ${ }^{40}$

\section{Limitations}

This study had several limitations, most inherent to retrospective studies. First, there were no controls of similar age and sex distribution, so it is not clear whether the results could be generalized to inpatients in other clinical settings. Second, the present study was at risk of misclassification and selection bias. Third, the sample size in our study was small and limited due to logistical and institutional constraints. In addition, the impact of multiple psychiatric diagnoses obscured the relationship of specific individual diagnoses on vitamin D levels.

\section{Conclusion}

Monitoring of vitamin D levels on hospital admission for psychiatric illness and supplementation of vitamin D may be an important and beneficial strategy, especially for African Americans. Supplements are generally safe and easy to administer. Other interventions to prevent vitamin D insufficiency among this population could also be considered at the community level, including adequate sunlight exposure and dietary balance. In addition, it could be of important diagnostic value to monitor vitamin $\mathrm{D}$ levels as a routine screening test in all psychiatric patients. Further studies are needed to explore the explicit role of vitamin D in the causality of psychiatric illness, but the present data further highlight the need for awareness of this issue among behavioral health providers.

\section{Disclosure}

The authors report no conflicts of interest in this work.

\section{References}

1. Norman AW. From vitamin D to hormone D: fundamentals of the vitamin $\mathrm{D}$ endocrine system essential for good health. Am J Clin Nutr. 2008;88(2):491S-499S.

2. Holick MF. Vitamin D deficiency. N Engl J Med. 2007;357(3): 266-281.

3. Cui X, Gooch H, Groves NJ, et al. Vitamin D and the brain: key questions for future research. J Steroid Biochem Mol Biol. 2015;148:305-309.

4. McGrath J. Hypothesis: is low prenatal vitamin $D$ a risk-modifying factor for schizophrenia? Schizophr Res. 1999;40(3):173-177.

5. Cannell JJ. Autism and vitamin D. Med Hypotheses. 2008;70(4): 750-759.

6. Eyles DW, Feron F, Cui X, et al. Developmental vitamin D deficiency causes abnormal brain development. Psychoneuroendocrinology. 2009; 34(Suppl 1):S247-S257.

7. Kesby JP, Cui X, O'Loan J, McGrath JJ, Burne TH, Eyles DW. Developmental vitamin D deficiency alters dopamine-mediated behaviors and dopamine transporter function in adult female rats. Psychopharmacology. 2009;208(1):159-168.

8. Armstrong DJ, Meenagh GK, Bickle I, Lee AS, Curran ES, Finch MB. Vitamin D deficiency is associated with anxiety and depression in fibromyalgia. Clin Rheumatol. 2007;26(4):551-554.

9. Hoang MT, Defina LF, Willis BL, Leonard DS, Weiner MF, Brown ES. Association between low serum 25-hydroxyvitamin $\mathrm{D}$ and depression in a large sample of healthy adults: the Cooper Center longitudinal study. Mayo Clin Proc. 2011;86(11):1050-1055. 
10. Annweiler C, Schott AM, Berrut G, et al. Vitamin D and ageing: neurological issues. Neuropsychobiology. 2010;62(3):139-150.

11. Berk M, Jacka FN, Williams LJ, Ng F, Dodd S, Pasco JA. Is this $\mathrm{D}$ vitamin to worry about? Vitamin D insufficiency in an inpatient sample. Aust N Z J Psychiatry. 2008;42(10):874-878.

12. Rylander M, Verhulst S. Vitamin D insufficiency in psychiatric inpatients. J Psychiatr Pract. 2013;19(4):296-300

13. JóZefowicz O, Rabe-Jabłońska J, Woźniacka A, Strzelecki D. Analysis of vitamin D status in major depression. J Psychiatr Pract. 2014;20(5): 329-337.

14. Black LJ, Jacoby P, Allen KL, et al. Low vitamin D levels are associated with symptoms of depression in young adult males. Aust $N Z J$ Psychiatry. 2014;48(5):464-471.

15. Schneider B, Weber B, Frensch A, Stein J, Fritz J. Vitamin D in schizophrenia, major depression and alcoholism. J Neural Transm (Vienna). 2000;107(7):839-842.

16. Itzhaky D, Amital D, Gorden K, Bogomolni A, Arnson Y, Amital H. Low serum vitamin $\mathrm{D}$ concentrations in patients with schizophrenia Isr Med Assoc J. 2012;14(2):88-92.

17. Valipour G, Saneei P, Esmaillzadeh A. Serum vitamin D levels in relation to schizophrenia: a systematic review and meta-analysis of observational studies. J Clin Endocrinol Metab. 2014;99(10):3863-3872.

18. Ford J, Hategan A, Bourgeois JA, Tisi DK. Hypovitaminosis d: a contributor to psychiatric disorders in elderly? Can Geriatr J. 2012;15(3): $80-84$.

19. Grudet C, Malm J, Westrin A, Brundin L. Suicidal patients are deficient in vitamin $\mathrm{D}$, associated with a pro-inflammatory status in the blood. Psychoneuroendocrinology. 2014;50:210-219.

20. Martins D, Wolf M, Pan D, et al. Prevalence of cardiovascular risk factors and the serum levels of 25-hydroxyvitamin D in the United States: data from the Third National Health and Nutrition Examination Survey. Arch Intern Med. 2007;167(11):1159-1165.

21. Cole CR, Grant FK, Tangpricha V, et al. 25-Hydroxyvitamin D status of healthy, low-income, minority children in Atlanta, Georgia. Pediatrics. 2010;125(4):633-639.

22. McCue RE, Charles RA, Orendain GC, Joseph MD, Abanishe JO. Vitamin D deficiency among psychiatric inpatients. Prim Care Companion CNS Disord. 2012;14(2):pii: PCC.11m01230.

23. Harris HR, Chavarro JE, Malspeis S, Willett WC, Missmer SA. Dairyfood, calcium, magnesium, and vitamin D intake and endometriosis a prospective cohort study. Am J Epidemiol. 2013;177(5):420-430.

24. Berg AO, Melle I, Torjesen PA, Lien L, Hauff E, Andreassen OA. A cross-sectional study of vitamin $\mathrm{D}$ deficiency among immigrants and Norwegians with psychosis compared to the general population. $J$ Clin Psychiatry. 2010;71(12):1598-1604.

25. Takiishi T, Gysemans C, Bouillon R, Mathieu C. Vitamin D and diabetes. Endocrinol Metab Clin North Am. 2010;39(2):419-446.

26. Humble MB. Vitamin D, light and mental health. $J$ Photochem Photobiol B. 2010;101(2):142-149.

27. Cardinal RN, Gregory CA. Osteomalacia and vitamin D deficiency in a psychiatric rehabilitation unit: case report and survey. BMC Res Notes. 2009;2:82.

28. Menkes DB, Lancaster K, Grant M, Marsh RW, Dean P, du Toit SA Vitamin D status of psychiatric inpatients in New Zealand's Waikato region. BMC Psychiatry. 2012;12:68.

29. Zittermann A, Prokop S. The role of vitamin D for cardiovascular disease and overall mortality. Adv Exp Med Biol. 2014;810:106-119.

30. Rendina D, De Filippo G, Muscariello R, et al. Vitamin D and cardiometabolic disorders. High Blood Press Cardiovasc Prev. 2014;21(4): 251-256

31. Ramadan R, Vaccarino V, Esteves F, et al. Association of vitamin D status with mental stress-induced myocardial ischemia in patients with coronary artery disease. Psychosom Med. 2014;76(7):569-575.

32. Pludowski P, Holick MF, Pilz S, et al. Vitamin D effects on musculoskeletal health, immunity, autoimmunity, cardiovascular disease, cancer, fertility, pregnancy, dementia and mortality-a review of recent evidence. Autoimmun Rev. 2013;12(10):976-989.
33. Penckofer S, Kouba J, Byrn M, Estwing Ferrans C. Vitamin D and depression: where is all the sunshine? Issues Ment Health Nurs. 2010; 31(6):385-393.

34. Eyles DW, Smith S, Kinobe R, Hewison M, McGrath JJ. Distribution of the vitamin D receptor and 1 alpha-hydroxylase in human brain. J Chem Neuroanat. 2005;29(1):21-30.

35. Gezen-Ak D, Dursun E, Yilmazer S. The effects of vitamin D receptor silencing on the expression of LVSCC-A1C and LVSCC-A1D and the release of NGF in cortical neurons. PLoS One. 2011;6(3): e17553.

36. Jacob JA. As New Orleans looks to the future, questions remain on Hurricane Katrina's long-term mental health effects. JAMA. 2015;314(9):863-865.

37. Hansel T, Osofsky H, Osofsky J, Speier A. Longer-term mental and behavioral health effects of the deepwater horizon gulf oil spill. J Mar Sci Eng. 2015;3(4):1260-1271.

38. Public Affairs Research Council of Louisiana. Public Mental Health Care in Louisiana, An Analysis of Louisiana's Fragmented System of Care and Options for Reform. Baton Rouge: Public Affairs Research Council of Louisiana; 2009, Publication 322.

39. US Department of Health and Human Services. Strategies for Integrating and Coordinating Care for Behavioral Health Populations: Case Studies of Four States. Washington: US Department of Health and Human Services, Office for the Assistant Secretary for Planning and Evaluation; 2014

40. Ford ES, Ajani UA, McGuire LC, Liu S. Concentrations of serum vitamin D and the metabolic syndrome among U.S. adults. Diabetes Care. 2005;28(5):1228-1230.

41. Zeng Q, Dellenbaugh T, Maldonado M, Moon J, Hornstra R. Vitamin D status of psychiatric inpatients at a community teaching hospital in the Midwest. Nord J Psychiatry. 2016;70(3):208-214.

42. Humble MB, Gustafsson S, Bejerot S. Low serum levels of 25-hydroxyvitamin D (25-OHD) among psychiatric out-patients in Sweden: relations with season, age, ethnic origin and psychiatric diagnosis. J Steroid Biochem Mol Biol. 2010;121(1-2):467-470.

43. United States Centers for Disease Control. Vitamin D Status: United States, 2001-2006. Available from: http://www.cdc.gov/nchs/data/ databriefs/db59.pdf. Accessed August 25, 2016.

44. Abdullah AK, Khan S, Mustafa SF, Qutubuddin AA, Davis CM. Vitamin D status and cardiometabolic risk factors in long-term psychiatric inpatients. Prim Care Companion CNS Disord. 2012;14(1): PCC. $11 \mathrm{~m} 01221$.

45. Guan A, Gong H, Ye Y, et al. Regulation of $\mathrm{p} 53$ by jagged 1 contributes to angiotensin II-induced impairment of myocardial angiogenesis. PLoS One. 2013;8(10):e76529.

46. Kendell RE, Adams W. Exposure to sunlight, vitamin D and schizophrenia. Schizophrenia Res. 2002;54(3):193-198.

47. Kimlin MG, Olds WJ, Moore MR. Location and vitamin D synthesis: is the hypothesis validated by geophysical data? J Photochem Photobiol B. 2007;86(3):234-239.

48. Lucas JA, Bolland MJ, Grey AB, et al. Determinants of vitamin D status in older women living in a subtropical climate. Osteoporos Int. 2005; 16(12):1641-1648.

49. Pasco JA, Henry MJ, Kotowicz MA, et al. Seasonal periodicity of serum vitamin $\mathrm{D}$ and parathyroid hormone, bone resorption, and fractures: the Geelong Osteoporosis Study. J Bone Miner Res. 2004;19(5):752-758.

50. Binkley N, Krueger DC, Morgan S, Wiebe D. Current status of clinical 25-hydroxyvitamin D measurement: an assessment of between-laboratory agreement. Clin Chim Acta. 2010;411(23-24):1976-1982.

51. United State Census Bureau. QuickFacts, New Orleans City, Louisiana. New Orleans City: United State Census Bureau; 2015.

52. Chen TC, Chimeh F, Lu Z, et al. Factors that influence the cutaneous synthesis and dietary sources of vitamin D. Arch Biochem Biophys. 2007;460(2):213-217.

53. Clemens TL, Adams JS, Henderson SL, Holick MF. Increased skin pigment reduces the capacity of skin to synthesise vitamin D3. Lancet. 1982;1(8263):74-76. 
54. McGrath J, Selten JP, Chant D. Long-term trends in sunshine duration and its association with schizophrenia birth rates and age at first registration - data from Australia and the Netherlands. Schizophr Res. 2002;54(3):199-212.
55. Kinney DK, Teixeira P, Hsu D, et al. Relation of schizophrenia prevalence to latitude, climate, fish consumption, infant mortality, and skin color: a role for prenatal vitamin d deficiency and infections? Schizophr Bull. 2009;35(3):582-595.

\section{Publish your work in this journal}

Neuropsychiatric Disease and Treatment is an international, peerreviewed journal of clinical therapeutics and pharmacology focusing on concise rapid reporting of clinical or pre-clinical studies on a range of neuropsychiatric and neurological disorders. This journal is indexed on PubMed Central, the 'PsycINFO' database and CAS, and is the official journal of The International Neuropsychiatric Association (INA). The manuscript management system is completely online and includes a very quick and fair peer-review system, which is all easy to use. Visit http://www.dovepress.com/testimonials.php to read real quotes from published authors.

Submit your manuscript here: http://www.dovepress.com/neuropsychiatric-disease-and-treatment-journal 